\title{
Axial phenoxide coordination on di-iron(III) bisporphyrin: Insights from experimental and DFT studies
}

\author{
SUSOVAN BHOWMIK, DEBANGSU SIL, RANJAN PATRA and SANKAR PRASAD RATH* \\ Department of Chemistry, Indian Institute of Technology Kanpur, Kanpur 208016, India \\ e-mail: sprath@iitk.ac.in
}

\begin{abstract}
Synthesis, structure and properties of new five-coordinate phenolate complexes of di-iron(III) bisporphyrin are reported here, in which phenol binds in $\eta^{1}$-fashion as an axial ligand. The solid and solution EPR at $120 \mathrm{~K}$ and ${ }^{1} \mathrm{H}$ NMR spectral pattern in solution provide unequivocal evidence for the high spin $(\mathrm{S}=5 / 2)$ nature of the complex. Mulliken spin density calculation using DFT demonstrates the positive spin densities at the meso carbons and negative spin densities at the methylene carbons and, as a result, the meso and methylene protons are shifted in the upfield and down field regions, respectively in the ${ }^{1} \mathrm{H}$ NMR spectra of the molecule. Also, the ortho- and para-protons of the phenolate ligands are observed to be shifted in the upfield region while meta-protons are shifted downfield. The alternating shift pattern, which is the opposite sign of the chemical shifts for meta-versus ortho- and para-protons, was also explained due to negative and positive spin densities, respectively on the carbons and indicative of $\pi$ spin delocalization on the phenolate ligand. Thus, the calculated spin density maps accounted for the essential ${ }^{1} \mathrm{H}$ NMR spectroscopic features that are observed here for the phenolate complexes of di-iron(III) bisporphyrin. The temperature dependence of the signals follows the Curie law which is indicative of single spin state throughout the temperature range of -40 to $+40^{\circ} \mathrm{C}$. The single crystal X-ray structure of the corresponding chloro derivative, trans 1,2-bis(chloroiron(III) octaethyl porphyrinyl)ethene, has also been reported here which authenticates the high-spin nature of the complex.
\end{abstract}

Keywords. Molecular spin; phenolate complex; spin density calculation; structure elucidation.

\section{Introduction}

Elucidation of the electronic structure of iron porphyrin is quite important in order to understand the function and catalytic activities of naturally occurring heme proteins. ${ }^{1-5}$ Extensive work on model system and hemoproteins have established that the axial ligand coordination along with the nature of the macrocycles are strong determinant of the electronic structure and function of the chromophore. ${ }^{1-5}$ Recently, we have reported very different electronic structure and properties of $\mathrm{Fe}(\mathrm{III})$ complexes while using bisporphyrin architecture as compared to the corresponding monoporphyrin. ${ }^{1,3}$ For example, $\mathrm{ClO}_{4}^{-}$, being a relatively weak field ligand, generally stabilizes complexes with intermediate/admixed intermediate-spin of $\mathrm{Fe}$ (III), while $\mathrm{CF}_{3} \mathrm{SO}_{3}^{-}$forms mostly spin-admixed complexes with predominately high-spin contributions. ${ }^{1,2}$ However, stabilization of the pure intermediate-spin of iron in a di-iron(III) bisporphyrin with $\mathrm{CF}_{3} \mathrm{SO}_{3}^{-}$as the axial ligand has been observed, while with $\mathrm{ClO}_{4}^{-}$, a high-spin

*For correspondence complex is formed. Thus, the complete reversal of the ligand field strength of $\mathrm{ClO}_{4}^{-}$and $\mathrm{CF}_{3} \mathrm{SO}_{3}^{-}$in the magnetochemical series is observed in a di-iron(III) bisporphyrin framework. ${ }^{\text {la }}$ Deformations of the porphyrin macrocycles in a bisporphyrin framework have been demonstrated to play the key role for such unusual behaviour. ${ }^{1,3}$ This has prompted us to investigate further the effect of axial ligands as a part of our general program on bisporphyrin. ${ }^{6}$

In the present work, we have investigated the binding of phenols as axial ligand on a di-iron(III) bisporphyrin framework and compared the electronic structure and properties with the corresponding monoporphyrin complex of the same. Phenolate (porphinato)iron(III) complexes merit attention on the basis of tyrosine coordination to iron(III)porphyrin centres in catalase and certain mutant haemoglobin. ${ }^{7-10}$ In case of catalase, the role of axial phenolato ligand on the catalytic activity has not been properly investigated. ${ }^{10} \mathrm{How}-$ ever, phenolato binding to $\mathrm{Fe}(\mathrm{III})$ porphyrins are known for quite some time which forms five-coordinate complex where phenols bind in a $\eta^{1}$-binding mode. ${ }^{11,12}$ Trans-1,2-bis(meso-octaethylporphyrinyl)ethene are used in the present investigations in which two por- 
phyrin macrocycles are placed in the trans position of an ethene linker leading to strong electronic communications between them in a single molecular framework.

\section{Experimental}

\subsection{Materials}

The free base trans-1,2-bis (meso-octaethylporphyrinyl) ethene ${ }^{13}$ and trans-1,2-bis [chloroiron(III)5-(2,3,7,8,12, $13,17,18$-octaethylporphyrinyl)]ethene, $\mathbf{1}^{\text {6d }}$ have been synthesized using reported procedures. Reagents and solvents are purchased from the commercial sources and purified by standard procedures before use.

Complex $\mathbf{2}$ was prepared using a general procedure; details are given below for one representative case.

2.1a $2 a: \quad 100 \mathrm{mg}(0.079 \mathrm{mmol})$ of $\mathbf{1}$ was dissolved in $50 \mathrm{ml}$ dichloromethane. $16.36 \mathrm{mg}(0.174 \mathrm{mmol})$ phenol in $2 \mathrm{ml}$ dichloromethane was added to it and the resulting solution was then refluxed for $1 \mathrm{~h}$. The resulting solution was evaporated to complete dryness. The solid thus obtained was dissolved in minimum volume of dichloromethane, filtered to remove any solid residue and carefully layered with cyclohexane which was then kept for slow diffusion in air at room temperature. On standing for 6-7 days, dark purple crystalline solid was formed which was then collected by filtration, washed well with the mother liquor and dried in vacuum. Yield: $81 \mathrm{mg}$ (74\%). Anal. Calcd (found): C, 74.45 (74.33); $\mathrm{H}, 7.12$ (7.23); N, 8.08 (8.14). UV-vis (dichloromethane) $\left[\lambda_{\max }, \mathrm{nm}\left(\varepsilon, \mathrm{M}^{-1} \mathrm{~cm}^{-1}\right)\right]: 348\left(8.6 \times 10^{4}\right), 410(1.6 \times$ $\left.10^{5}\right), 503\left(9.9 \times 10^{3}\right), 547\left(5.2 \times 10^{2}\right), 621(3.3 \times$ $\left.10^{2}\right)$. ${ }^{1} \mathrm{H}$ NMR $\left(\mathrm{CDCl}_{3}, 295 \mathrm{~K}\right)$ : meso- $\mathrm{H}:-26.0$, $-45.2, \mathrm{CH}_{3}: 7.2,7.0,6.6, \mathrm{CH}_{2}: 31.9,34.9,42.3$, 43.2, 44.4, 48.7, 50.8; $\mathrm{CH}(\mathrm{b}): 88.5 ; m_{t}-H$ (phenol): 61.2; $p-H$ (phenol): $-73.2 ; o-H$ (phenol): $-82.1 \mathrm{ppm}$. EPR data: in solid $(120 \mathrm{~K}), \mathrm{g}_{\perp}=5.98$ and $\mathrm{g}_{\mathrm{II}}=1.99$; in dichloromethane $(120 \mathrm{~K}), \mathrm{g}_{\perp}=5.97$ and $\mathrm{g}_{\mathrm{II}}=1.99$.

2.1b 2b: Yield: $84 \mathrm{mg}(69 \%)$. Anal. Calcd (found): C, 66.85 (66.81); H, 6.26 (6.33); N, 7.25 (7.35). UVvis (dichloromethane) $\left[\lambda_{\max }, \mathrm{nm}\left(\varepsilon, \mathrm{M}^{-1} \mathrm{~cm}^{-1}\right)\right]: 355$ $\left(8.5 \times 10^{4}\right), 378\left(2.1 \times 10^{5}\right), 512\left(9.7 \times 10^{3}\right), 551$ $\left(5.1 \times 10^{2}\right), 632\left(3.3 \times 10^{2}\right) .{ }^{1} \mathrm{H} \mathrm{NMR}\left(\mathrm{CDCl}_{3}, 295 \mathrm{~K}\right)$ : meso- $\mathrm{H}:-26.8,-46.1, \mathrm{CH}_{3}: 7.2,7.0,6.8, \mathrm{CH}_{2}$ : 32.3, 34.1, 42.1, 42.3, 44.1, 48.4, 50.4; $\mathrm{CH}$ (b): 90.0; $m_{t}-H$ (phenol): $62.6 ; o-H$ (phenol): $-90.1 \mathrm{ppm}$. EPR data: in solid $(120 \mathrm{~K}), \mathrm{g}_{\perp}=5.97$ and $\mathrm{g}_{\mathrm{II}}=1.99$; in dichloromethane $(120 \mathrm{~K}), \mathrm{g}_{\perp}=5.98$ and $\mathrm{g}_{\mathrm{II}}=2.00$. 2.1c 2c: Yield: $90 \mathrm{mg}(73 \%) 72 \mathrm{mg}$ (58\%). Anal. Calcd (found): C, 65.89 (65.77); H, 6.04 (6.15); N, 10.72 (10.77). UV-vis (dichloromethane) $\left[\lambda_{\max }, \mathrm{nm}(\varepsilon\right.$, $\left.\mathrm{M}^{-1} \mathrm{~cm}^{-1}\right)$ ]: $357\left(1.9 \times 10^{5}\right), 399\left(7.9 \times 10^{4}\right), 515(8.3$ $\left.\times 10^{3}\right), 543\left(5.7 \times 10^{2}\right), 633\left(3.3 \times 10^{2}\right) .{ }^{1} \mathrm{H}$ NMR $\left(\mathrm{CDCl}_{3}, 295 \mathrm{~K}\right)$ : meso- $\mathrm{H}$ : $-25.8,-45.6, \mathrm{CH}_{3}: 6.1,5.7$, 5.2, $\mathrm{CH}_{2}$ : 32.6, 35.5, 43.6, 44.6, 46.0, 50.0, 51.6, 57.6; $\mathrm{CH}$ (b): 90.7; $p-H$ (phenol): $-73.6, o-H$ (phenol): $-84.4 \mathrm{ppm}$. EPR data: in solid $(120 \mathrm{~K}), \mathrm{g}_{\perp}=5.96$ and $\mathrm{g}_{\mathrm{II}}=2.00$; in dichloromethane $(120 \mathrm{~K}), \mathrm{g}_{\perp}=5.98$ and $\mathrm{g}_{\mathrm{II}}=1.99$.

2.1d 2d: Yield: $87 \mathrm{mg}(77 \%)$. Anal. Calcd (found): C, 74.88 (74.71); H, 7.40 (7.39); N, 7.76 (8.01). UVvis (dichloromethane) $\left[\lambda_{\max }, \mathrm{nm}\left(\varepsilon, \mathrm{M}^{-1} \mathrm{~cm}^{-1}\right)\right]: 347$ $\left(8.3 \times 10^{4}\right), 381\left(1.8 \times 10^{5}\right), 505\left(9.6 \times 10^{3}\right), 539$ $\left(5.4 \times 10^{2}\right), 623\left(3.1 \times 10^{2}\right) .{ }^{1} \mathrm{H}$ NMR $\left(\mathrm{CDCl}_{3}, 295 \mathrm{~K}\right)$ : meso- $\mathrm{H}$ : $-31.9,-48.6, \mathrm{CH}_{3}: 7.3,7.2,7.0, \mathrm{CH}_{2}$ : 31.6, $37.3,40.2,41.6,42.2,44.2,47.5 ; \mathrm{CH}(\mathrm{b}): 88.8 ; m_{t^{-}}$ $\mathrm{CH}_{3}$ (phenol): $-30.8 ; p-H$ (phenol): -89.2 . EPR data: in solid $(120 \mathrm{~K}), \mathrm{g}_{\perp}=5.95$ and $\mathrm{g}_{\mathrm{II}}=1.99$; in dichloromethane $(120 \mathrm{~K}), \mathrm{g}_{\perp}=5.99$ and $\mathrm{g}_{\mathrm{II}}=2.00$.

\subsection{Instrumentation}

UV-vis spectra were recorded on a PerkinElmer UV/vis spectrometer. Elemental $(\mathrm{C}, \mathrm{H}$, and $\mathrm{N})$ analyses were performed on CE-440 elemental analyzer. ESI-MS spectra were recorded on a Waters Micromass Quattro Micro triple quadropole mass spectrometer. ${ }^{1} \mathrm{H}$ NMR spectra were recorded on a JEOL $500 \mathrm{MHz}$ instrument. The spectra for paramagnetic molecules were recorded over a $100 \mathrm{KHz}$ bandwidth with $64 \mathrm{~K}$ data points and a $5 \mu \mathrm{s} 90^{\circ}$ pulse. For a typical spectrum between 2000 and 3000 transients were accumulated with a $50 \mathrm{~ms}$ delay time. The residual ${ }^{1} \mathrm{H}$ resonances of the solvents were used as a secondary reference. Electron paramagnetic resonance (EPR) spectra were obtained on a Bruker EMX EPR spectrometer.

\section{$2.3 X$-ray structure solution and refinement}

Crystals were coated with light hydrocarbon oil and mounted in the $100 \mathrm{~K}$ dinitrogen stream of Bruker SMART APEX CCD diffractometer equipped with CRYO Industries low-temperature apparatus. Intensity data were collected using graphite-monochromated Mo $\mathrm{K} \alpha$ radiation $(\lambda=0.71073 \AA)$ while SAINT software was used for data integration and reduction. ${ }^{14}$ 
Table 1. Crystal data and data collection parameters of $1 \cdot 2 \mathrm{CH}_{2} \mathrm{Cl}_{2}$.

\begin{tabular}{|c|c|}
\hline$T, \mathrm{~K}$ & $100(2)$ \\
\hline Formula & $\mathrm{C}_{78} \mathrm{H}_{96} \mathrm{Fe}_{2} \mathrm{~N}_{8} \mathrm{Cl}_{10}$ \\
\hline Crystal size $\left(\mathrm{mm}^{3}\right)$ & $0.26 \times 0.22 \times 0.15$ \\
\hline Formula weight & 1611.83 \\
\hline Colour & Dark red \\
\hline Crystal system & Monoclinic \\
\hline Space group & $\mathrm{P} 2{ }_{1} / \mathrm{c}$ \\
\hline$a, \AA$ & $10.986(5)$ \\
\hline$b, \AA$ & $15.012(5)$ \\
\hline$c, \AA$ & $24.151(5)$ \\
\hline$\alpha$, deg & 90 \\
\hline$\beta, \operatorname{deg}$ & $100.240(5)$ \\
\hline$\gamma, \operatorname{deg}$ & 90 \\
\hline$V, \AA^{3}$ & $3920(2)$ \\
\hline $\operatorname{Radiation}(\lambda, \AA)$ & Mo K $\alpha(0.71073)$ \\
\hline$Z$ & 2 \\
\hline$d_{\text {calcd }}, \mathrm{g} \cdot \mathrm{cm}^{-3}$ & 1.366 \\
\hline$\mu, \mathrm{mm}^{-1}$ & 0.759 \\
\hline$F(000)$ & 1684 \\
\hline$\theta$ range of data collection $\left(^{\circ}\right)$ & 2.19 to 25.50 \\
\hline Reflections collected & 16579 \\
\hline Independent reflections & $7218[\mathrm{R}(\mathrm{int})=0.073]$ \\
\hline Observed reflections $[I>2 \sigma(I)]$ & 7218 \\
\hline Completeness to $\theta_{\max }$ & $98.9 \%$ \\
\hline Max. and min. transmission & 0.895 and 0.827 \\
\hline No. of restraints & 0 \\
\hline No. of params. refined & 450 \\
\hline GOF on $F^{2}$ & 1.076 \\
\hline $\mathrm{R} 1^{\mathrm{a}}[I>2 \sigma(I)]$ & 0.0973 \\
\hline $\mathrm{R} 1^{\mathrm{a}}$ (all data) & 0.1455 \\
\hline $\mathrm{w} R 2^{\mathrm{b}}$ (all data) & 0.2305 \\
\hline \multicolumn{2}{|l|}{${ }^{\mathrm{a}} R 1=\frac{\sum|| F_{O}|-| F_{C} \|}{\sum\left|F_{O}\right|}$} \\
\hline${ }^{\mathrm{b}} w R 2=\sqrt{\frac{\sum\left[w\left(F o^{2}-F c^{2}\right)^{2}\right]}{\sum\left[w\left(F o^{2}\right)^{2}\right]}}$. & \\
\hline
\end{tabular}

An absorption correction was applied. ${ }^{15}$ The structure was solved by the direct method using SHELXS97 and was refined on $\mathrm{F}^{2}$ by full-matrix least-squares technique using the SHELXL-97 program package. ${ }^{16}$ Non-hydrogen atoms were refined anisotropically. In the refinement, hydrogens were treated as riding atoms using SHELXL default parameters. Crystal data and data collection parameters are given in table 1 .

\subsection{Computational details}

DFT calculations have been carried out by employing a B3LYP hybrid functional using the Gaussian 03, revision B.04, package. ${ }^{17}$ The method used was Becke's three parameter hybrid exchange functional, the nonlocal correlation provided by the Lee, Yang, and Parr expression, and Vosko, Wilk, and Nuair 1980 correlation functional (III) for local correction. ${ }^{18,19}$ The basis set was LanL2DZ for iron atom and $6-31 \mathrm{G}^{* *}$ for carbon, nitrogen, oxygen, and hydrogen atoms. For $\mathbf{2 a}$, the porphyrin coordinates are taken from the single crystal $\mathrm{X}$-ray data of $\mathbf{1}$. However, phenol coordinates are taken from the X-ray structure of the corresponding monoporphyrin, $\mathrm{Fe}^{\mathrm{III}}(\mathrm{OEP})(\mathrm{OPh}){ }^{11 \text { a }}$ All the calculations were performed with a multiplicity of 11 and no structural relaxations were carried out.

\section{Results and discussion}

The free base ligand, trans-1,2-bis(mesooctaethylporphyrinyl)ethene, has been synthesized using the reported procedure. ${ }^{13}$ In a degassed solvent mixture of $\mathrm{CH}_{3} \mathrm{CN}$ and $\mathrm{CHCl}_{3}$ (2:1), free ligand was treated with excess $\mathrm{FeCl}_{2}$ at $55^{\circ} \mathrm{C}$ for $30 \mathrm{~min}$ under $\mathrm{N}_{2}$ atmosphere which upon aerial oxidation and subsequent chromatographic purifications yields dark red trans 1,2-bis(chloroiron(III) octaethyl porphyrinyl)ethene, $\mathbf{1}$ as reported previously. ${ }^{6 \mathrm{~d}}$ The UV-vis spectrum of $\mathbf{1}$ in dichloromethane shows two well resolved $B_{\perp}$ and $B_{\|}$transitions at 391 and $412 \mathrm{~nm}$ in dichloromethane indicative of trans-conformation of the molecule. Although some of the spectral characterizations of 1 have recently been reported by us, ${ }^{6 \mathrm{~d}}$ the single crystal X-ray structure of the complex has been reported here and compared with the similar structures reported in the literature. ${ }^{1 \mathrm{a}, 20}$ Upon addition of phenols into a dichloromethane solution of $\mathbf{1}$, the UV-vis spectral changes have been observed due to the formation of five-coordinate phenolate complex 2 which was then isolated in pure form and spectroscopically characterized. With phenol, complex 2a has been isolated which shows UV-visible spectra with a Soret band at $410 \mathrm{~nm}$ and three Q bands at 503, 547 and $621 \mathrm{~nm}$. Similar spectral features are also observed for the complexes with other substituted phenols (4-bromo phenol, 3,5-dinitro phenol and 3,5-dimethyl phenol). Under identical conditions, the five-coordinate $\mathrm{Fe}^{\mathrm{III}}(\mathrm{OEP})(\mathrm{OPh})$ shows a Soret band at $391 \mathrm{~nm}$ and also three Q-bands at 490, 520 and $603 \mathrm{~nm}$, which suggests a coordination number of five for the phenolato complexes 2 as reported here. ${ }^{11 a}$ Scheme 1 shows the synthetic outline of all the complexes reported here along with their abbreviations, while figure 1 shows the UV-vis spectra of the representative complexes. However, detailed synthetic procedures along with the spectroscopic characterizations are given in the Experimental section (vide supra). 

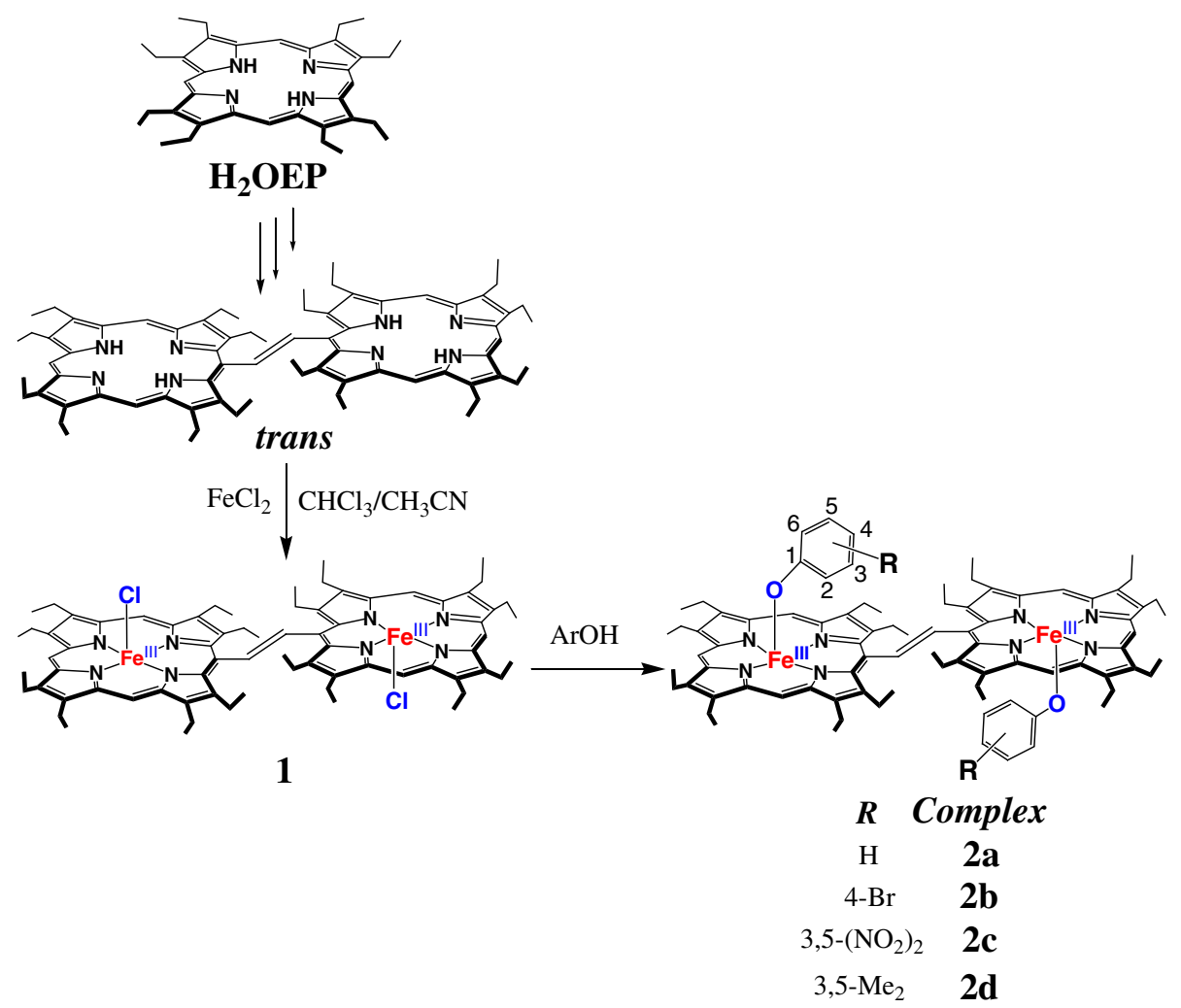

Scheme 1. Synthetic outline of the complex.

Inspite of several attempts, we are unable to get X-ray quality crystals of $\mathbf{2}$ suitable for structure determinations, however, the electronic structure and properties of the molecules are determined using several other spectroscopic techniques successfully. ESI mass spectral analysis of $\mathbf{2 d}$ was done which reveals a signal at $\mathrm{m} / \mathrm{z}, 1465.70$ assigned for $[\mathbf{2 d}+\mathrm{Na}]^{+}$. The isotopic distribution pattern of experimental mass is also exactly matched with the theoretical pattern as displayed in figure 2 .

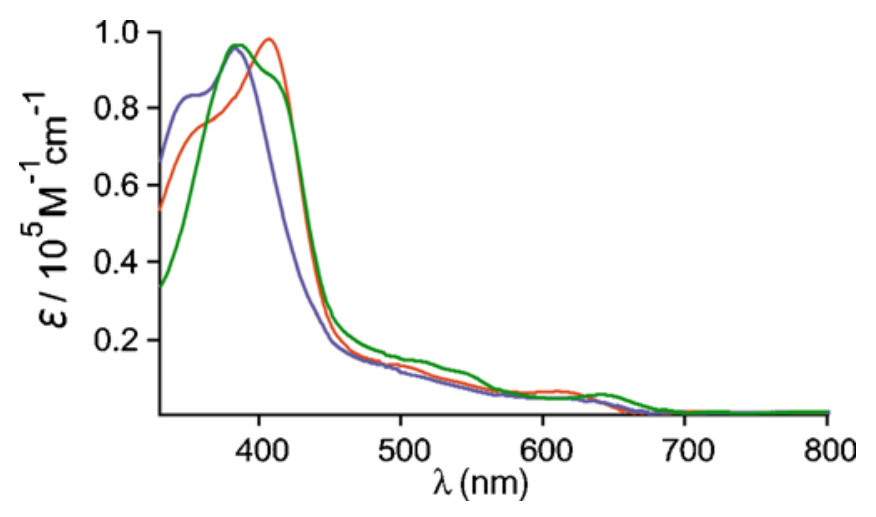

Figure 1. UV-visible spectra in dichloromethane for $\mathbf{1}$ (green line), 2a (red line) and $\mathbf{2 d}$ (blue line) at $295 \mathrm{~K}$.

\subsection{Crystallographic characterization of 1}

Slow diffusion of cyclohexane into a dichloromethane solution of the molecule at room temperature gave dark red crystals from which an appropriate crystal was chosen for X-ray structure determination. The molecule crystallizes in the monoclinic crystal system with $P 2_{1} / c$ space group and, in an asymmetric unit, one half molecule of the complex and one dichloromethane solvent molecule is present. A perspective view of the molecule is shown in figure 3 and the selected bond distances and angles are given in table 2. The $\mathrm{Fe}-$ $\mathrm{Cl}$ and the average $\mathrm{Fe}-\mathrm{N}$ bond length are 2.241(2) and 2.055(6) $\AA$, respectively that are 'normal' for a high-spin iron(III)porphyrin with axial chloride ion. ${ }^{21}$ The iron is displaced by $0.56 \AA$ from the least-square plane of $\mathrm{C}_{20} \mathrm{~N}_{4}$ porphyrinato core, a distance that are higher than that of the typical range of $0.39-0.54 \AA$ generally observed for five-coordinate high-spin (S, $5 / 2$ ) iron(III) porphyrins. The porphyrin ring is considerably distorted with an average deviation of $0.21 \AA$ from planarity, while the meso carbons that are connected through the bridging ligand are displaced most. This is presumably to minimize the non-bonded contact between the two macrocycles and $\mathrm{Fe}$. . Fe non- 
(a)

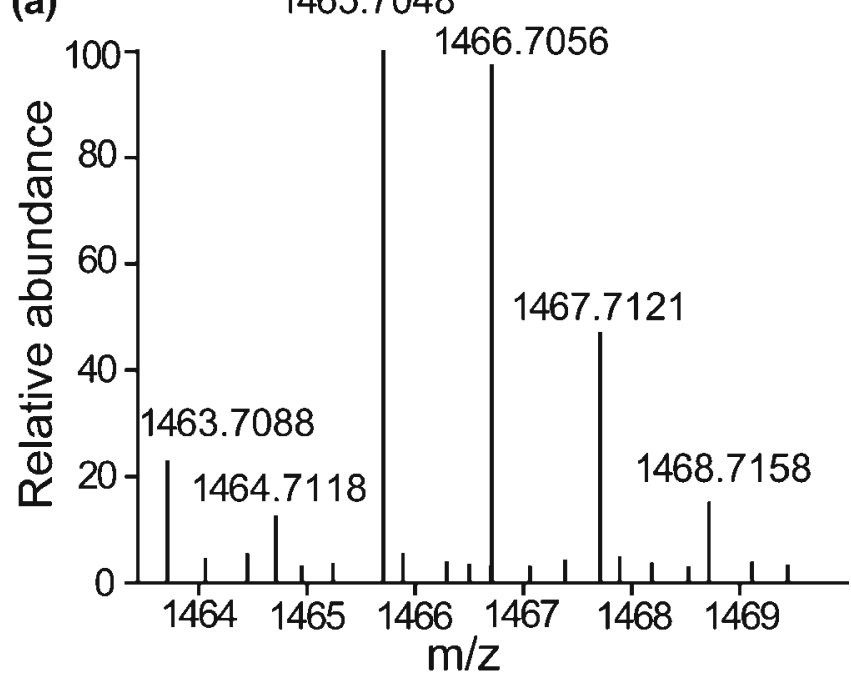

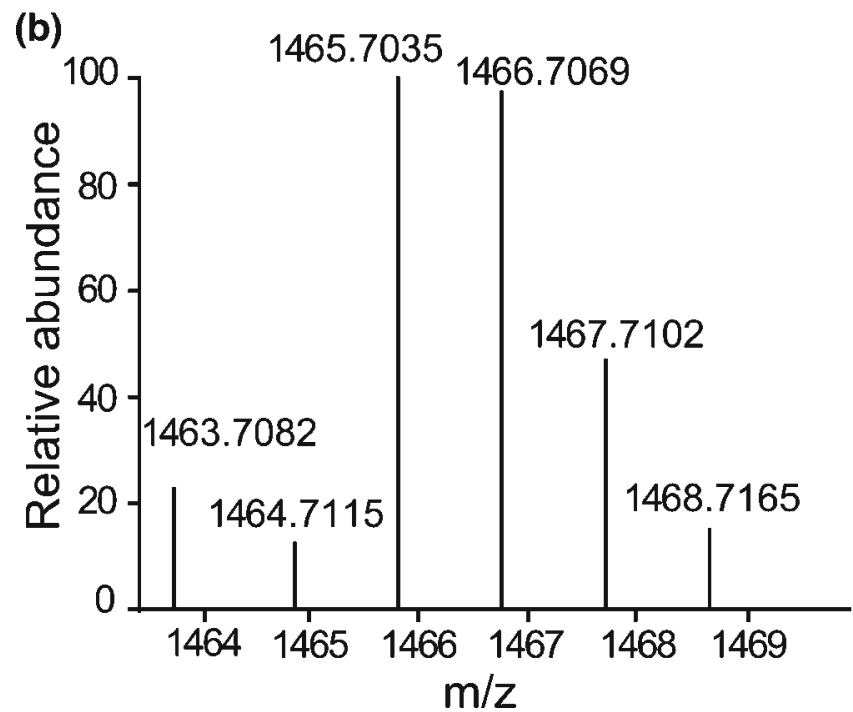

Figure 2. Isotopic distribution of the (a) experimental and (b) theoretical ESI-MS of $[2 \mathbf{d}+\mathrm{Na}]^{+}$.
Table 2. Selected bond lengths $(\AA)$ and bond angles $\left(^{\circ}\right)$ for $\mathbf{1} \cdot 2 \mathrm{CH}_{2} \mathrm{Cl}_{2}$.

\begin{tabular}{lr} 
Fe1-Cl1 & $2.241(2)$ \\
Fe1-N1 & $2.051(5)$ \\
Fe1-N2 & $2.057(6)$ \\
Fe1-N3 & $2.062(5)$ \\
Fe1-N4 & $2.050(6)$ \\
Cl1-Fe1-N1 & $103.40(16)$ \\
C11-Fe1-N2 & $108.49(17)$ \\
Cl1-Fe1-N3 & $104.62(16)$ \\
Cl1-Fe1-N4 & $96.94(16)$ \\
N1-Fe1-N4 & $85.7(2)$ \\
N2-Fe1-N4 & $154.6(2)$ \\
N1-Fe1-N2 & $87.4(2)$ \\
N3-Fe1-N4 & $88.4(2)$ \\
N2-Fe1-N3 & $86.2(2)$ \\
N1-Fe1-N3 & $151.9(2)$ \\
\hline
\end{tabular}

bonding distance is found to be $9.84 \AA$. The crystal packing shows the formation of well-separated stacks of molecules as illustrated in figure 4 . Table 3 compares all the key structural parameters of the molecule 1 reported here along with structurally characterized high-spin $\mathrm{Fe}$ (III) bisporphyrins coordinated to the axial ligands reported in the literature (shown in chart 1).

\section{$3.2{ }^{1} H N M R$}

Figures $5 \mathrm{a}$ and $\mathrm{b}$ show the ${ }^{1} \mathrm{H}$ NMR spectra in $\mathrm{CDCl}_{3}$ at $295 \mathrm{~K}$ for $\mathbf{1}$ and 2a, respectively. The signals are broad and shifted both upfield and downfield regions indicative of $\pi$-spin delocalization. The basic resonance pattern of porphyrin core for the phenolate complex $\mathbf{2}$ are grossly similar with the high-spin complex $\mathbf{1}$, which also follow the pattern seen for meso-R-substituted fivecoordinate complex of type $\mathrm{XFe}^{\mathrm{III}}$ (meso-R-OEP). It is

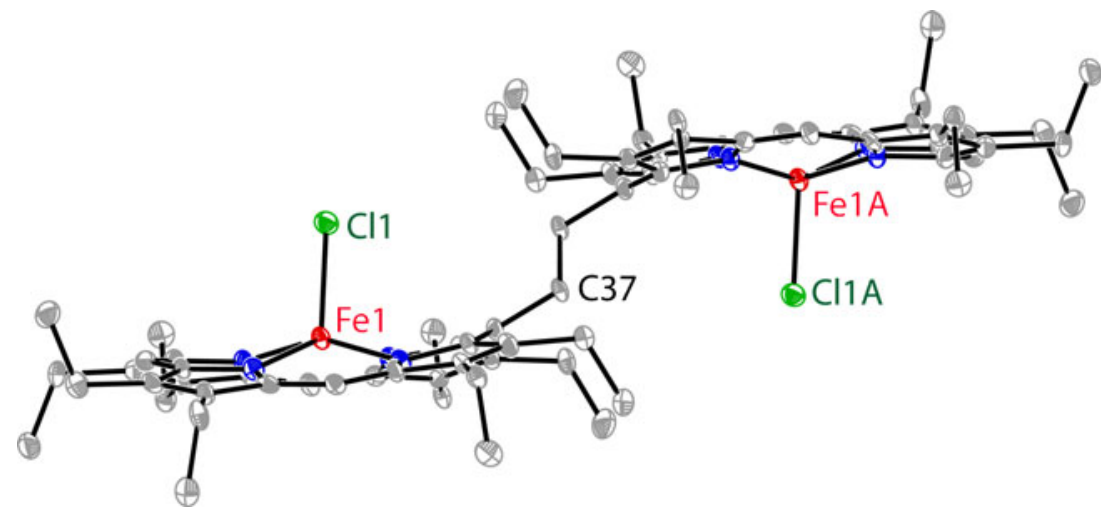

Figure 3. A perspective view of $\mathbf{1} \cdot 2 \mathrm{CH}_{2} \mathrm{Cl}_{2}$ showing $50 \%$ thermal contours for all non-hydrogen atoms at $100 \mathrm{~K}$ (H-atoms and two $\mathrm{CH}_{2} \mathrm{Cl}_{2}$ solvent molecules have been omitted for clarity). 


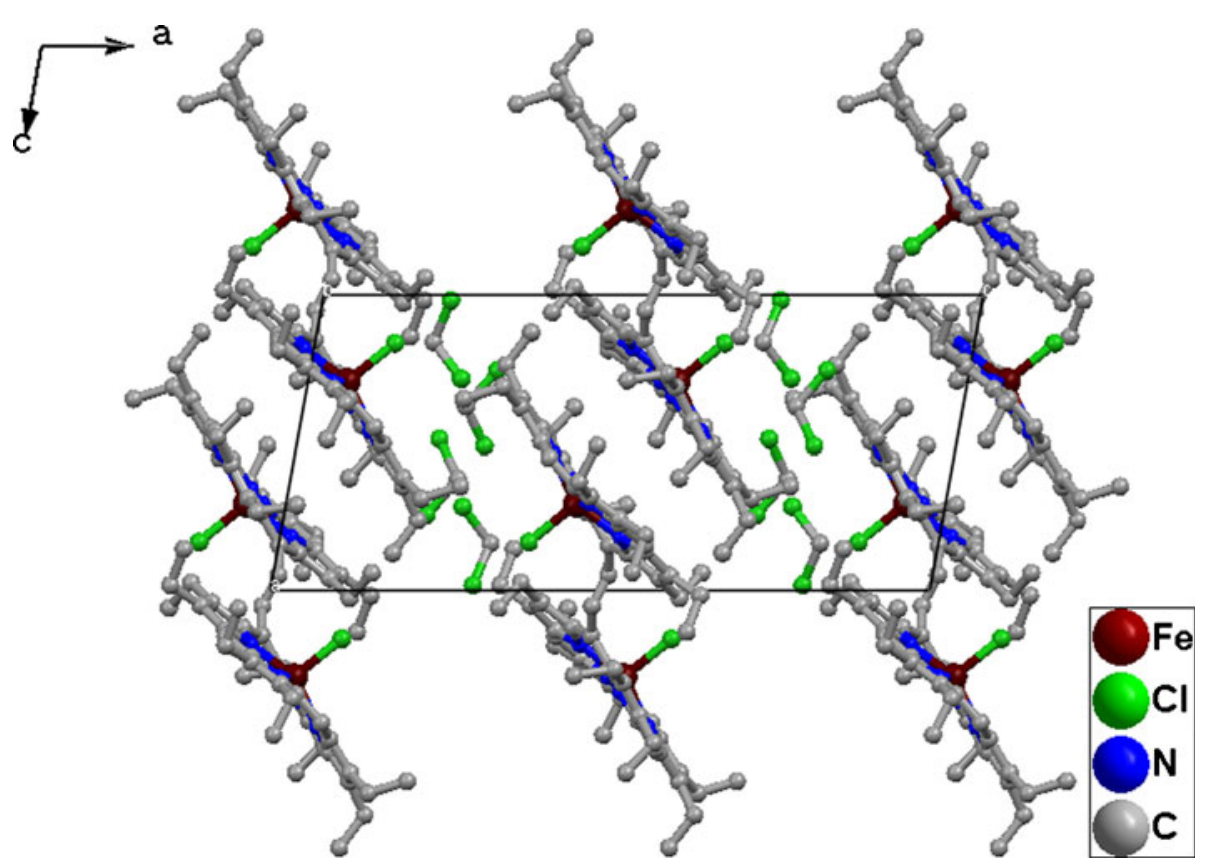

Figure 4. Diagram illustrating the packing of $\mathbf{1} \cdot 2 \mathrm{CH}_{2} \mathrm{Cl}_{2}$ in the unit cell.
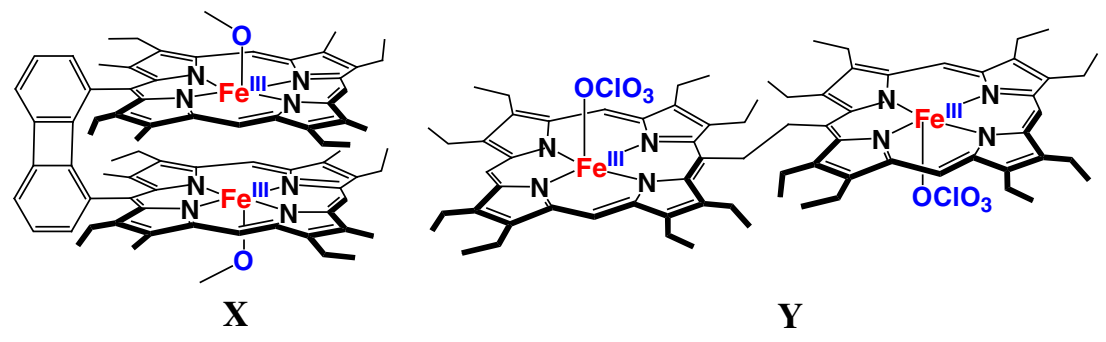

Chart 1.

Table 3. Selected structural parameters for high-spin axially ligated $\mathrm{Fe}^{\mathrm{III}}$ (bisporphyrin) core.

\begin{tabular}{lllllllllc}
\hline Complex & $\mathrm{Fe}_{\mathrm{N}}{ }^{\mathrm{a}}$ & $\mathrm{Fe}-\mathrm{L}^{\mathrm{b}}$ & $\Delta_{4 \mathrm{~N}}^{\mathrm{Fe}}$ & $\Delta_{24}{ }^{\mathrm{d}}$ & $\mathrm{C}_{\mathrm{m}}{ }^{\mathrm{e}}$ & $\mathrm{C}_{\beta}{ }^{\mathrm{e}}$ & $\mathrm{MPS}^{\mathrm{f}}$ & $\mathrm{Fe} \cdot \cdots \mathrm{Fe}^{\mathrm{g}}$ & Refs. \\
\hline $\mathrm{X}$ & 2.073 & 1.834 & 0.43 & 0.07 & 0.03 & 0.13 & 3.45 & 10.04 & 20 \\
$\mathrm{Y}$ & $2.060(9)$ & $1.906(9)$ & 0.43 & 0.11 & 0.15 & 0.15 & 3.16 & 4.55 & $1 \mathrm{a}$ \\
$\mathbf{1}$ & $2.055(6)$ & $2.241(2)$ & 0.48 & 0.21 & 0.38 & 0.18 & 3.52 & 9.84 & This work \\
\hline
\end{tabular}

average value in $\AA$.

b Average distance (in $\AA$ ) of axial ligand L.

${ }^{c}$ Displacement of iron from the mean plane containing four porphyrinic nitrogen.

${ }^{\mathrm{d}}$ Average displacement of atoms from the least-squares plane of $\mathrm{C}_{20} \mathrm{~N}_{4}$ porphyrinato core.

${ }^{\mathrm{e}}$ Average displacement of the respective carbons from mean plane of $\mathrm{C}_{20} \mathrm{~N}_{4}$ porphyrinato core.

${ }^{\mathrm{f}}$ Average distance between two least-squares plane of $\mathrm{C}_{20} \mathrm{~N}_{4}$ porphyrinato core.

${ }^{g}$ Non-bonding distance (in $\AA$ ) between two Fe(III)-centres in a molecule. 

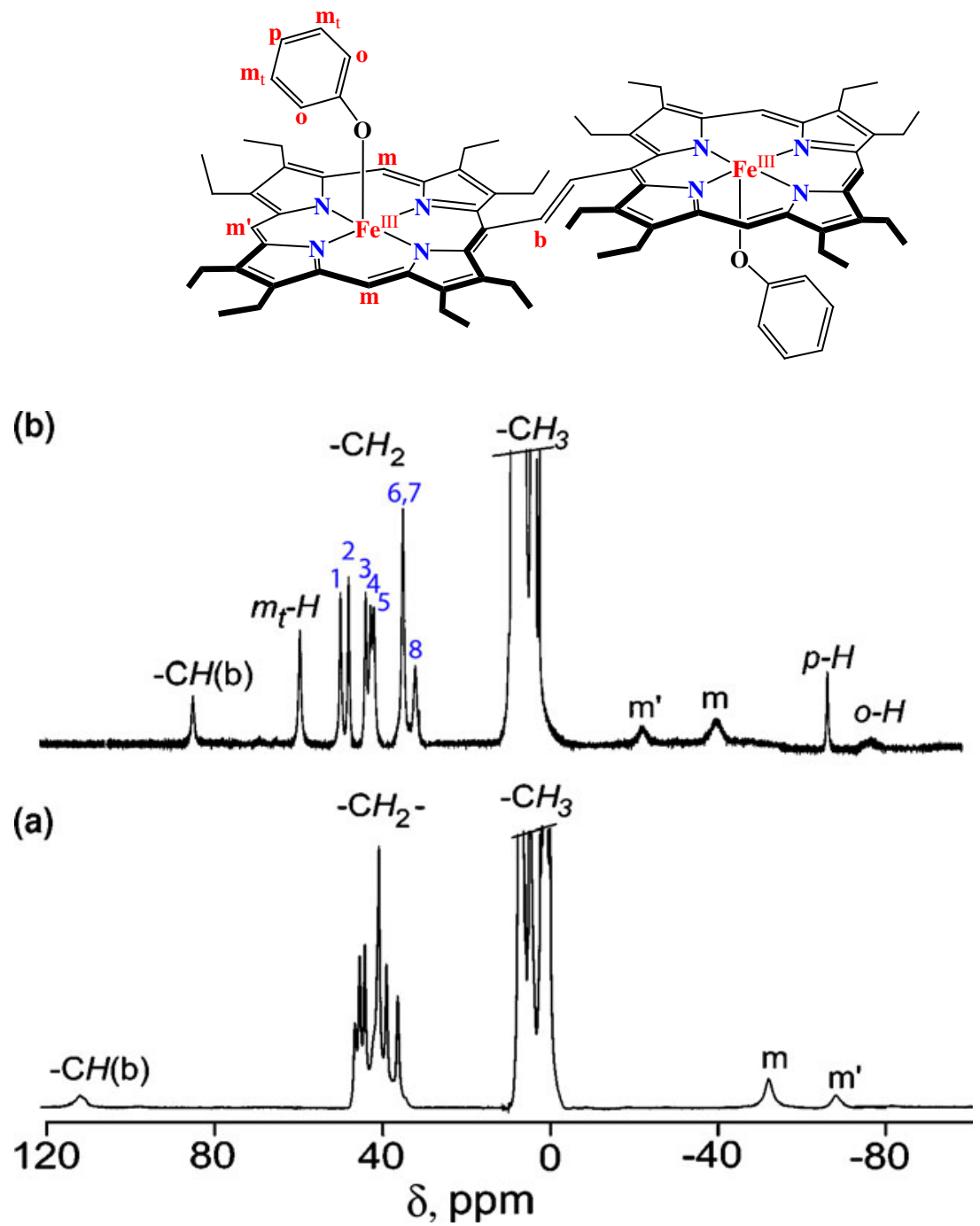

Figure 5. ${ }^{1} \mathrm{H}$ NMR spectra of (a) $\mathbf{1}$ and (b) $\mathbf{2 a}$ in $\mathrm{CDCl}_{3}$ at $295 \mathrm{~K}$ (inset shows the proton numbering scheme).

therefore expected that there should be two meso resonances in 2:1 intensity ratio, eight methylene resonances, and four equally intense methyl resonances for a five-coordinate complex. The eight methylene resonances arise from the diastereotopic nature of these protons which occurs whenever the two sides of the porphyrin are inequivalent. As can be seen in figure 5, there are two resonances in the far upfield region with a 2:1 intensity ratio (assigned to the meso protons), and eight resonances in the downfield region that can be assigned to the methylene protons. The bridging $-\mathrm{CH}$ shows one resonance at the most downfield region. As expected, the resonances for methyl protons are found within the narrow diamagnetic region since they are far off from the metal centre. For 2a, eight diastereotopic methylene signals come at 31.9, 34.9, 42.3, 43.2, 44.4, 48.7 and $50.8 \mathrm{ppm}$, two meso resonances at -45.2 and
$-26.0 \mathrm{ppm}$ in $2: 1$ intensity ratios while the bridging ethylene signal comes at $88.5 \mathrm{ppm}$. Similar spectral features are also observed for other phenolate complexes (2b-2d) reported here and compared in figure 6. The temperature dependence of the signals follows the Curie law as shown in figure 7 indicative of single spin state throughout the temperature range of -40 to $+40^{\circ} \mathrm{C} .{ }^{1,3-5}$ Moreover, the positioning of the methylene and meso signals provide unequivocal evidence for the high spin $(\mathrm{S}=5 / 2)$ nature of $\mathbf{2}$ in solution. The magnetic moment of $2 \mathbf{a}$ at $295 \mathrm{~K}$ in the purified dichloromethane was also calculated using modified Evan's method ${ }^{22}$ which shows the magnetic moment of 5.86 BM per iron, as also expected for a high-spin complex.

However, the phenolate resonances of $\mathbf{2 a}$ are shifted both up and down field regions as reflected in figure $5 \mathrm{~b}$ which indicates $\pi$-spin delocalization on the 


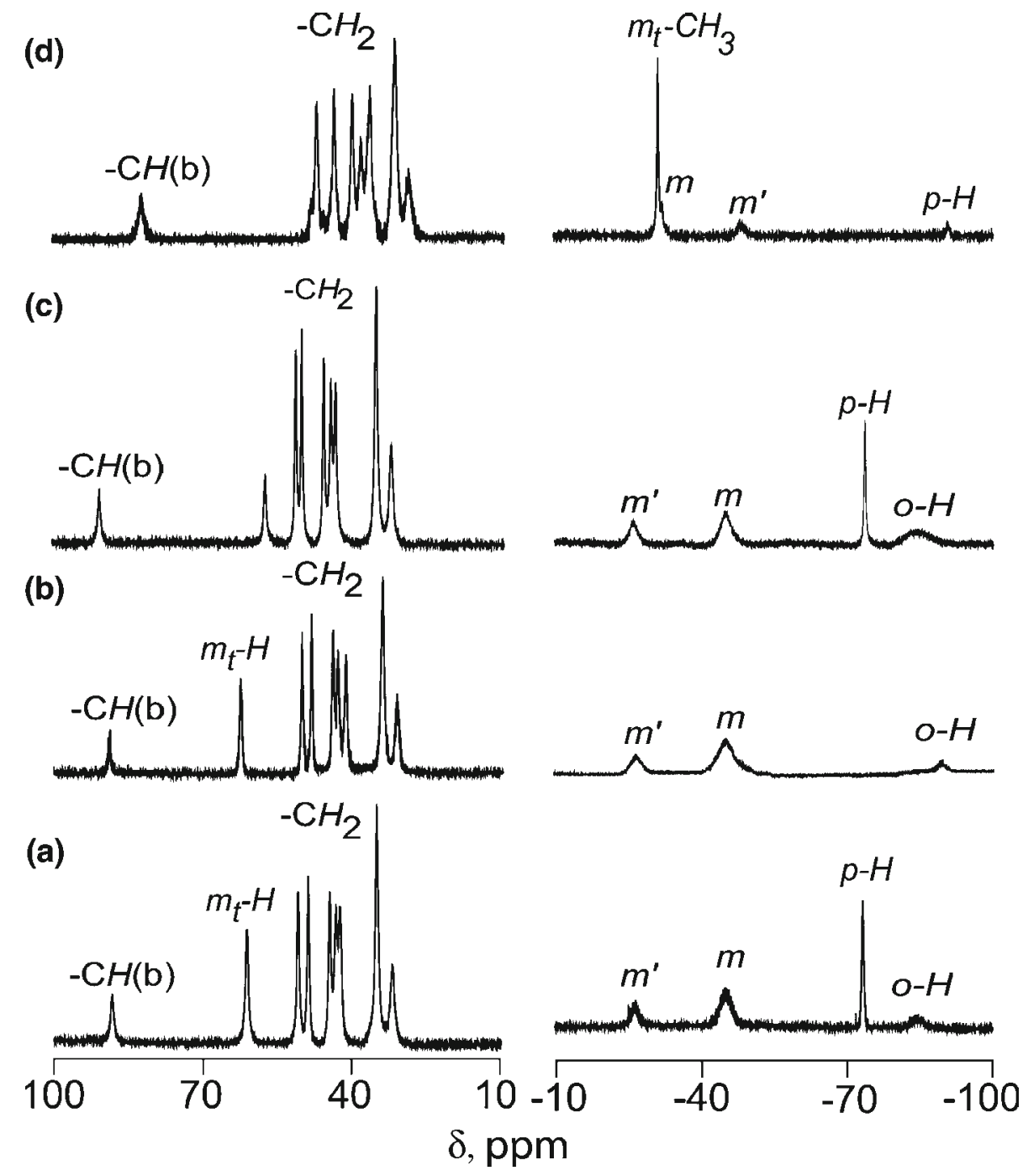

Figure 6. ${ }^{1} \mathrm{H}$ NMR spectra of (a) 2a, (b) $2 \mathbf{b}$, (c) $2 \mathbf{c}$ and (d) $2 \mathbf{d}$ in $\mathrm{CDCl}_{3}$ at $295 \mathrm{~K}$.

phenolate ligand. The ortho protons of axial phenolate ligand are closest to the paramagnetic Fe centre and have extremely small $T_{1}$ (spin-lattice relaxation) values resulting in very broad signal at $-82.1 \mathrm{ppm}$. The meta and para proton resonances are relatively sharp and found at 61.2 and $-73.2 \mathrm{ppm}$, respectively. In order to assign the peaks of the phenolato moiety successfully, various substituted phenols have been used and figure 6 which compares the ${ }^{1} \mathrm{H}$ NMR spectra of all the phenolate complexes reported here. As can be seen, the ortho- and paraprotons show upfield shifts in the ${ }^{1} \mathrm{H}$ NMR spectra while meta-protons show downfield shifts. Similar observations are also reported when thiolates and catecholates are used as axial ligands. ${ }^{12,23}$

Figure 8A demonstrates the Mulliken spin densities using DFT of the phenolato carbons for 2a in which spin densities observed positive at ortho and para posi-

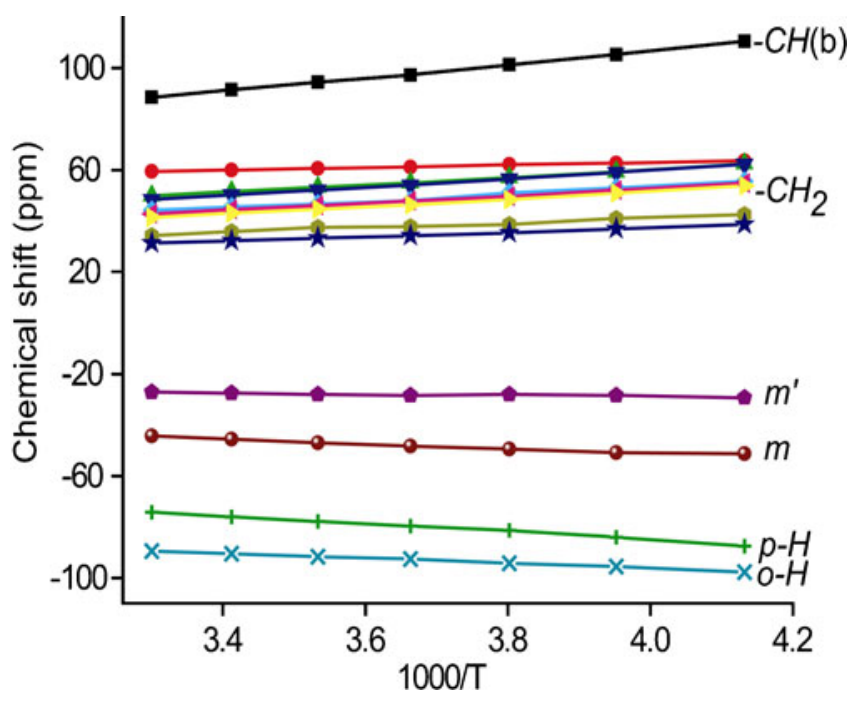

Figure 7. Curie plots (chemical shift versus $1 / \mathrm{T}$ ) of some proton signals for $\mathbf{2 c}$. 


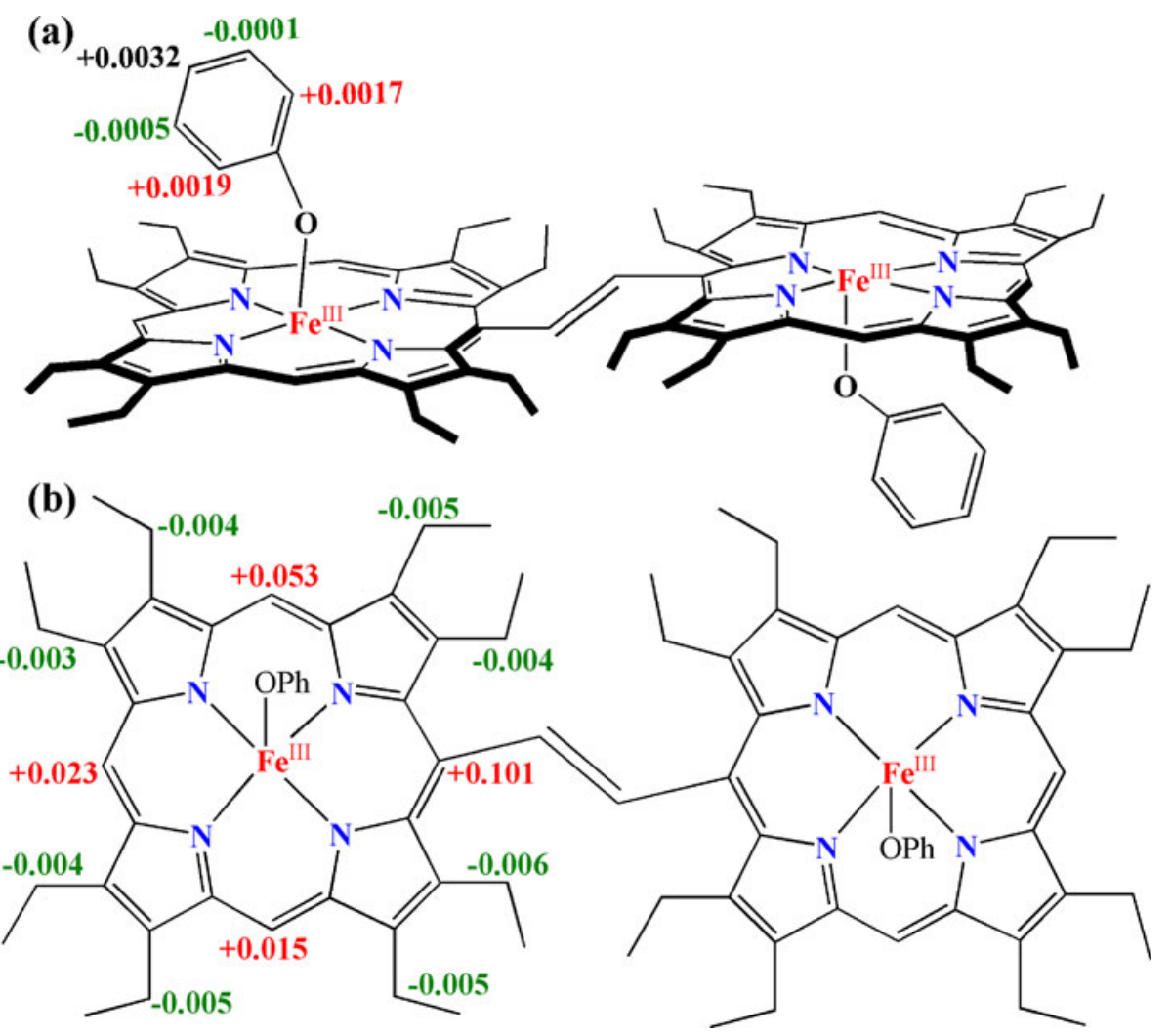

Figure 8. Mulliken spin densities calculated for $\mathbf{2 a}$ of (a) phenolato carbons and (b) porphyrin meso- and ethylene carbons are shown.

tions, while negative at meta positions. As a result, the ortho- and para-protons would be shifted upfield while meta-protons in the downfield region as also observed in the ${ }^{1} \mathrm{H}$ NMR of the molecule. The alternating shift pattern, which is the opposite sign of the chemical shifts for meta versus ortho and para-protons, is also indicative of $\pi$ spin delocalization on the phenolate ligand.

Figure $8 \mathrm{~b}$, however, displays the Mulliken spin densities calculated at the meso and ethylene carbons of porphyrin macrocyle for 2a. Mulliken spin population analysis demonstrates the positive spin densities at the meso carbons (thus, responsible for upfield shift of the meso protons) out of which the meso carbons at the cis positions have higher spin densities compared to trans resulting more upfield shifts of meso protons of the cis positions (figure 6). Also, Mulliken spin densities of methylene carbons have negative values and, as a result, the methylene protons are shifted in the down field regions as also observed in ${ }^{1} \mathrm{H}$ NMR spectra of the molecule. Thus, the spin density calculations qualitatively explain the nature and positioning of the proton signals. Similar theoretical calculations have also (c)

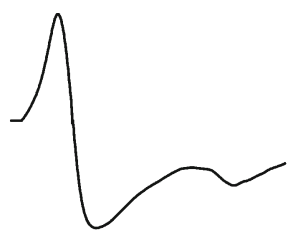

(b)

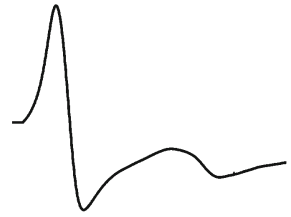

(a)

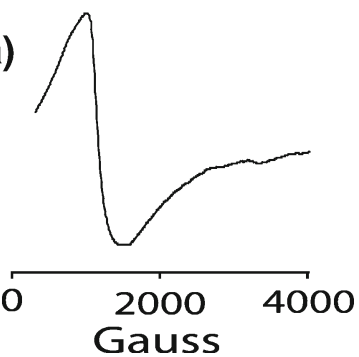

Figure 9. X-band EPR spectra of (a) 1, (b) 2a and (c) 2b in $\mathrm{CH}_{2} \mathrm{Cl}_{2}$ at $120 \mathrm{~K}$. 
been performed earlier in order to explain the ${ }^{1} \mathrm{H}$ NMR shift patterns of the molecules with paramagnetic metal ions. ${ }^{12,23,24}$

\section{$3.3 E P R$}

The EPR spectral measurements are carried out at $120 \mathrm{~K}$ both in solid and solution. The spectra are axially symmetric with $\mathrm{g}_{\perp}=5.97$ and $\mathrm{g}_{\mathrm{II}}=1.99$ for $\mathbf{2 a}$ and $\mathrm{g}_{\perp}=5.98$ and $\mathrm{g}_{\mathrm{II}}=2.00$ for $\mathbf{2 b}$ in dichloromethane. Very similar $g$ values are also obtained for other phenolate complexes in solution and also for all the molecules in solid (see Experimental section, vide supra). The representative spectra are shown in figure 9 along with the high-spin complex $\mathbf{1}$. These results are also suggestive of high spin $\mathrm{Fe}(\mathrm{III})(\mathrm{S}=5 / 2)$ nature of the complex 2 both in solid and solution.

\section{Conclusion}

Synthesis, structures and properties of new fivecoordinate phenolate complexes of di-iron(III)bisporphyrin 2 are reported here in which phenol binds in $\eta^{1}$-fashion as an axial ligand. The single crystal X-ray structure of the corresponding chloro complex, trans 1,2-bis(chloroiron(III) octaethyl porphyrinyl)ethene, 1 has also been reported here which authenticates the high-spin nature of the complex. Mulliken spin density calculation on 2a using DFT demonstrates the positive spin densities at the meso carbons while ethylene carbons have negative values and, as a result, the meso and methylene protons are shifted in the upfield and down field regions respectively in ${ }^{1} \mathrm{H}$ NMR spectra of the molecule. The positioning of the methylene and meso signals provide unequivocal evidence for the high spin $(S=5 / 2)$ nature of 2 in solution phase. The temperature dependence of the signals follows the Curie law which is indicative of single spin state throughout the temperature range of -40 to $+40^{\circ} \mathrm{C}$. The solid and solution EPR observations are also characteristics of high spin nature of the complexes.

Molecular orbital calculations using DFT show the electron spin densities are also spreaded over phenolate ligand. The ortho- and para-protons of phenolate ligands shifted upfield while meta-protons shifted downfield regions. The alternating shift pattern, thus observed, is due to negative and positive spin densities, respectively on plenolate carbons and indicative of $\pi$ spin delocalization on the phenolate ligand. Thus, the calculated spin density maps accounted for the essential ${ }^{1} \mathrm{H}$ NMR spectroscopic features that are observed for the phenolate complexes of di-iron(III) bisporphyrins are reported here.

\section{Supporting information}

CCDC-832929 contain the X-ray crystallographic details in CIF format for compound $\mathbf{1}$. The data can be obtained free of charge at www.ccdc.cam.ac.uk/ conts/retrieving.html or [from the Cambridge Crystallographic Data Center, 12 Union Road, Cambridge CB2 1EZ, UK; Fax: +44 1223336 033; E-mail: deposit@ccdc.cam.ac.uk].

\section{Acknowledgements}

We are thankful to the Department of Science and Technology (DST), and Council of Scientific and Industrial Research (CSIR), New Delhi for financial support. SB, DS and RP thank CSIR, for their fellowships.

\section{References}

1. (a) Bhowmik S, Ghosh S K and Rath S P 2011 Chem. Commun. 47 4790; (b) Ghosh S K, Patra R and Rath S P 2010 Inorg. Chem. 493449

2. (a) Evans D R and Reed C A $2000 \mathrm{~J}$. Am. Chem. Soc. 122 4660; (b) Reed C A and Guiset F 1996 J. Am. Chem. Soc. 1183281

3. Ghosh S K and Rath S P 2010 J. Am. Chem. Soc. 132 17983

4. (a) Nakamura M 2006 Coord. Chem. Rev. 250 2271; (b) Shelnutt J A, Song X -Z, Ma J -G, Jia S -L, Jentzen W and Medforth C J 1998 Chem. Soc. Rev. 2731

5. Weiss R, Gold A and Terner J 2006 Chem. Rev. 106 2550

6. (a) Chaudhary A and Rath S P 2011 Chem. Eur. J. 17 11478; (b) Chaudhary A, Patra R and Rath S P 2011 Indian J. Chem. 50A 1436; (c) Brahma S, Ikbal Sk A and Rath S P 2011 Inorg. Chim. Acta 372 62; (d) Ghosh S K, Patra R and Rath S P 2010 Inorg. Chim. Acta 363 2791; (e) Ghosh S K, Patra R and Rath S P 2008 Inorg. Chem. 4710196

7. (a) Watanabe $\mathrm{Y}$, Nakajima $\mathrm{H}$ and Ueno $\mathrm{T} 2007$ Acc. Chem. Res. 40 554; (b) Watanabe Y and Fujii H, In Metal-Oxo and Metal-Peroxo Species in Catalytic Oxidations; Meunier B, Ed.; Springer: New York, 2000; Vol. 97, pp 61-89

8. Hersleth H P, Ryde U, Rydberg P, Görbitz C H and Andersson K K 2006 J. Inorg. Biochem. 100460

9. Kirkman H N and Gaetani G F 2007 Trends Biochem. Sci. 3244

10. Putnam C D, Arvai A S, Bourne Y and Tainer J A 2000 J. Mol. Biol. 296295

11. (a) Kanamori D, Yamada Y, Onoda A, Okamura T, Adachi S, Yamamoto H and Ueyama N 2005 Inorg. Chim. Acta. 358 331; (b) Ueyama N, Nishikawa N, Yamada Y, Okamura T and Nakamura A 1998 Inorg. 
Chim. Acta. 283 91; (c) Byrn M P, Curtis C J, Hsiou Y, Khan S, Sawin P A, Tendick S K, Terzis A and Strouse C E 1993 J. Am. Chem. Soc. 115 9480; (d) Helms A M, Jones W D and McLendon G L 1991 J. Coord. Chem. 23351

12. Chaudhary A, Patra R and Rath S P 2010 Eur. J. Inorg. Chem. 5211

13. (a) Arnold D, Johnson A W and Winter M 1997 J. Chem. Soc., Perkin Trans. 1 1643; (b) Ponomarev G V, Borovkov V V, Sugiura K, Sakata Y and Shul'ga A M 1993 Tetrahedron Lett. 342153

14. SAINT+ 19996.02 (ed) Bruker AXS, Madison, WI

15. Sheldrick G M 2000 SADABS 2.0

16. Sheldrick G M 1997 SHELXL-97: Program for Crystal Structure Refinement (Göttingen: University of Göttingen)

17. Frisch M J, Trucks G W, Schlegel H B, Scuseria G E, Robb M A, Cheeseman J R, Montgomery J A Jr, Vreven T, Kudin K N, Burant J C, Millam J M, Iyengar S S, Tomasi J, Barone V, Mennucci B, Cossi M, Scalmani G, Rega N, Petersson G A, Nakatsuji H, Hada M, Ehara M, Toyota K, Fukuda R, Hasegawa J, Ishida M, Nakajima T, Honda Y, Kitao O, Nakai H, Klene M, Li X, Knox J E, Hratchian H P, Cross J B, Bakken V, Adamo C, Jaramillo J, Gomperts R, Stratmann R E, Yazyev O, Austin A J, Cammi R, Pomelli C, Ochterski J W, Ayala P Y, Morokuma K, Voth G A, Salvador P,
Dannenberg J J, Zakrzewski V G, Dapprich S, Daniels A D, Strain M C, Farkas O, Malick D K, Rabuck A D, Raghavachari K, Foresman J B, Ortiz J V, Cui Q, Baboul A G, Clifford S, Cioslowski J, Stefanov B B, Liu G, Liashenko A, Piskorz P, Komaromi L, Martin $\mathrm{R}$ L, Fox D J, Keith T, Al-Laham M A, Peng C Y, Nanayakkara A, Challacombe M, Gill P M W, Johnson B, Chen W, Wong M W, Gonzalez C and Pople J A 2003 Gaussian 03, revision B.04; Gaussian, Inc.: Pittsburgh

18. Becke A D 1993 J. Chem. Phys. 985648

19. Lee C, Yang W and Parr R G 1988 Phys. Rev. B. 37785

20. Lee G-H 2003 Private communication

21. (a) Patra R, Chaudhary A, Ghosh S K and Rath S P 2008 Inorg. Chem. 47 8324; (b) Ohgo Y, Neya S, Ikeue T, Takahashi M, Takada N, Funasaki N and Nakamura M 2002 Inorg. Chem. 414627

22. Sur S K 1989 J. Magn. Res. 82169

23. (a) Ueyama N, Nishikawa N, Yamada Y, Okamura T, Oka S, Sakurai H and Nakamura A 1998 Inorg. Chem. 37 2415; (b) Ueyama N, Nishikawa N, Yamada Y, Okamura T and Nakamura A 1996 J. Am. Chem. Soc. 118 12826

24. (a) Szterenberg L, Latos-Grazynski L and Wojaczynski J 2002 Chem. Phys. Chem. 3 575; (b) Mao J, Zhang Y and Oldfield E 2002 J. Am. Chem. Soc. 124 13911 